\title{
Стратегии дистрибуции новостного контента в мессенджере Telegram
}

\author{
Дарья Соколова
}

Автор рассматривает российские СМИ, которые используют Telegram как дополнительную площадку дистрибуции контента с целью привлечения аудитории к своему сайту, и приходит к выводу, что в среднем СМИ публикуют в Telegram восемь сообщений в день, практически не используя видео- и аудиоматериалы. Исследование проводилось в два этапа -

в 2017 и 2018 гг.

Ключевые слова: мессенджер, Telegram, новости, медиаконтент, дистрибуция.

@ Соколова Дарья Валерьевна

кандидат филологических наук, старший преподаватель кафедры новых медиа и теории коммуникации факультета журналистики МГУ имени М.В. Ломоносова (г. Москва, Россия), darina0306@gmail.com

\section{Введение}

Проникновение Интернета за последние нескольких лет происходит в России за счет увеличения тех, кто использует для выхода в Сеть мобильные устройства (в первой половине 2019 г. - на 24\%, а число тех, кто пользуется исключительно мобильным интернетом, - на 50\%1). Медиакомпаниям приходится подстраиваться под особенности медиапотребления и предлагать контент на тех площадках, которым аудитория отдает предпочтение. Также при производстве и дистрибуции медиакотента учитываются особенности медиапотребления на мобильных устройствах: ограниченность восприятия длинных текстов, востребованность визуального контента, небольшая глубина просмотра ресурса, рассеянность внимания. Пользователь может в любой момент прервать чтение новостей и отвлечься на уведомление из социальных сетей или мессенджеров.

Согласно Web Index, в топ-10 самых популярных ресурсов у пользователей мобильного Интернета входят поисковые системы, социальные медиа, мессенджеры, «Сбербанк» и "Алиэкспресс»². Что касается данных, показывающих величину аудитории того или иного сервиса мгновенного обмена сообщениями, то статистика незначительно отличается у разных измерителей: 
по данным Mediascope, в тройку лидеров входят WhatsApp, Viber и Telegram³, по данным Deloitte, - WhatsApp, Viber и Skype ${ }^{4}$.

Востребованность мессенджеров у аудитории побудила СМИ обратить внимание на популярные площадки, однако опыт освоения мессенджеров был не всегда успешным. Немецкая Deutche Welle рассылала в WhatsApр тизеры своих новостей, но эксперимент пришлось завершить, поскольку аудитория слабо интересовалась тизерами и рассылка не приносила дохода. Российские СМИ еще не обратили внимания на потенциальную площадку дистрибуции контента, несмотря на то, что WhatsApp в 2018 г. внедрил функцию Broadcast Only для групповых чатов.

Другой мессенджер - Viber - позволяет СМИ создавать публичные аккаунты, однако лишь несколько федеральных СМИ регулярно размещают новости в своих аккаунтах. Коммуникация в данном случае исключительно односторонняя: пользователи не могут комментировать новости или общаться с редакцией.

С конца 2015 г. мессенджер Telegram открыл возможность создавать публичные каналы и боты. Многие СМИ, следуя за аудиторией, создали в мессенджере свои каналы. Telegram дает СМИ прямой доступ к аудитории, возможность мгновенно размещать сообщения, привлекать трафик к основной площадке. Кроме того, публиковать в Telegram-каналах любой тип контента (текстовый, визуальный, аудиальный, видео). Помимо дистрибуции контента мессенджер, несмотря на отсутствие привычных пользовательских интеракций (лайки, репосты, комментарии) и прямого фидбека от подписчиков, все же позволяет взаимодействовать с аудиторией. Специально созданные СМИ боты дают возможность получать от аудитории инфоповоды и UGC-контент.

Отметим, что мессенджер популярен не только у СМИ. В Telegram пришли популярные паблики «ВКонтакте» («Подслушано», MDK, «Шедевры рекламы» и др.), политические обозреватели и инсайдеры («Незыгарь», «Сталингулаг» и др.). Каждый пользователь может создать канал любой тематической направленности и нарастить собственную аудиторию. Мы также наблюдаем следующую тенденцию: популярные Telegram-каналы фактически заменяют собой традиционные массмедиа, информируя аудиторию о произошедших событиях или предлагая эксклюзивную информацию. Telegram-каналы с многотысячной аудиторией становятся источниками информации, на них ссылаются федеральные средства массовой коммуникации. A с 2017 г. компания Brand Analytics проводит мониторинг публичных каналов и чатов данного мессенджера, включая их в рейтинги цитируемости. По данным за январь 2020 г., Telegram является самой цитируемой платформой, обгоняя «Яндекс.Дзен» и агрегаторы «Новости.Mail.ru», «Рамблер.Новости»5. Согласно TGStat, значительная часть аудитории мессенджера (80\%) читает именно новостные каналы ${ }^{6}$, что подтверждает актуальность изучения даного контента в Telegram.

\section{0бзор литературы}

Мессенджеры изучаются медиаисследователями преимущественно как канал коммуникации между журналистами и источниками информации, журналистами и пиар-специалистами (Dodds, 2019; Kemp, 2018), реже - между журналистами и аудиторией (Domingo, Masip, Meijer, 2015). Причем в работах зарубежных медиаисследователей акцент делается на WhatsApp, а не на Telegram, что объяснимо географическими особенностями аудитории мессенджера: 72,6\% пользователей - россияне, в то время как среди некоторых европейских стран (Германия, Чехия, Латвия) доля пользователей колеблется в пределах $0,15-0,33 \%$. 
Функционирование Telegram, в том числе вопрос дистрибуции медиаконтента, недостаточно исследовано в российской и зарубежной науке. На данный момент медиаисследователи изучили историю развития и инструментарий (Mahin, 2016; Линд, Мaхов, 2016; Манукова, Захарова, 2017; Коноплев, 2017), безопасность данных (Jakobsen, 2015; Андрашитов, Иосебашвили, Цедилкин, 2016; Сейдаметов, Асанова, Костина, 2016), языковые особенности коммуникации в мессенджере (Голошубина, 2015).

В условиях законодательных ограничений свободы массовой информации Telegram-каналы рассматриваются как альтернативные источники информации и как площадки для новых лидеров мнений. Запуск Telegram-каналов удовлетворяет стремление авторов к самореализации и желание восполнить существующие пробелы в медиапространстве (Епишкин, 2017).

Исследователи пока не осмыслили место Telegram-каналов в медиасистеме, акцентируя внимание, скорее всего, на контенте, опубликованном в мессенджере. Отдельных исследований, посвященных дистрибуции медиаконтента, крайне мало, можно выделить опыт испанских локальных СМИ (Negreira-Rey, Lopez-Garcia, Lozano-Aguiar, 2017), белорусских (Степанов, 2018) и украинских СМИ (Чабаненко, 2018). Суммируя данные указанных исследований, можно констатировать, что Telegram - площадка, популярная в первую очередь у молодой аудитории (возрастная группа 18-34), которая ждет от средств массовой информации в мессенджере не автоматизированные републикации новостей, а более «человечную» подачу сообщений, заинтересованность в контакте.

Единственная работа посвящена использованию Telegram в рутинной работе журналистов (Градюшко, 2018), причем автор на основе опроса журналистов делает вывод, что перспективным направлением работы журналистов будет распространение контента с помощью публичных Telegramканалов.

\section{Методология исследования}

В рамках данной статьи представляется важным изучить стратегии дистрибуции медиаконтента в Telegram. Исследование проводилось в два этапа: первый был направлен на выявление особенностей дистрибуции новостного контента в Telegram, второй - на фиксацию изменений в стратегиях СМИ. Для контент-анализа были определены временные рамки (20 февраля - 5 марта 2017 г. и 15-24 февраля 2018 г.), которые не включали крупные события. Данный период позволяет оценить особенности контента и его дистрибуции без преобладания какой-либо тематики или значительного увеличения числа постов ввиду повестки дня. Всего проанализировано 1496 сообщений (839в первый период и 657 - во второй). Из выборки исключались рекламные и аналитические посты. Кодификатор включал следующие категории анализа: количество постов, время публикации, тип передачи контента, охват поста.

Отбор каналов для контент-анализа проводился по принципу разнообразия видов СМИ (периодическая печать, радио, телевидение, сетевые издания) и политических взглядов (прогосударственные и либеральные издания). В выборку вошли следующие СМИ: «Российская газета» (РГ), «Коммерсанъ», «Радио Свобода», ВВС Russian (BBC), «RT на русском» (RT), «Дождь», Meduza, «Сноб».

Первый этап исследования показал, что российские СМИ не выработали четкой контентной стратегии для мессенджера и рассматривали Telegram-каналы лишь как дополнительные площадки для привлечения аудитории на сайт СМИ. Исходя из этих результатов, были сформулированы вопросы для второго этапа исследования: Продолжает ли оставаться основной 
формой передачи контента сочетание текста и ссылки на сайт СМИ? Сохраняется ли зависимость охвата поста от частоты постинга (количества опубликованных сообщений в единицу времени)? Что для СМИ, присутствующих в Telegram, важнее - привести аудиторию из мессенджера на свой сайт или адаптировать контент под платформу и рассматривать мессенджер не только как дополнительную площадку для дистрибуции контента?

В данной статье подводятся итоги второго этапа исследования и посредством сравнительного анализа выявляются изменения в стратегиях дистрибуции новостного контента. Результаты первого этапа исследования подробно представлены в ранее опубликованной статье (Соколова, 2017).

\section{Основные результаты}

За период с 20 февраля по 5 марта 2017 г. среднее число подписчиков составляло около 11 тыс. человек. За год аудитория каналов значительно увеличилась - до 32,2 тыс. (см. табл. 1). Наибольшой рост отмечен у «Радио Свобода» (720\%, с 1860 до 13390 подписчиков), внушительный прирост показали также Meduza (353\%) и «Российской газеты» (343\%).

Частота постинга (см. табл. 2) в большинстве каналов осталась на прежнем уровне. Среднесуточное число публикуемых новостных сообщений - восемь. Значительные изменения произошли у канала «RT на русском»: среднее число сообщений в сутки уменьшилось с 15 до 2,7, при этом средний охват поста увеличился в два раза.

Иная картина наблюдается при изучении каналов "Дождь», Meduza, «Сноб»частота постинга во втором периоде увеличилась. Однако охват постов у «Дождя» и Meduza не претерпел серьезных изменений, а вот у "Сноба» данный показатель сократился с 72,6\% до 47,3\%. Собранные эмпирические данные (см. табл. 3) позволяют предположить, что высокая частота постинга напрямую влияет на охват: чем выше число публикуемых в сутки сообщений, тем ниже число просмотров. Это можно объяснить тем, что большое количество сообщений «отталкивает» аудиторию, которая отключает push-уведомления в чрезмерно активных каналах. Конечно, число проанализированных сообщений (1496) достаточно мало, поэтому полученные данные в достаточной степени условны, чтобы говорить о статистической значимости. В дальнейшем данные будут верифицированы на выборке большего объема, однако уже на данном этапе можно соотнести полученные данные с экспертизой smmспециалистов (Сенаторов, 2018) и статистикой ресурса Tgstat.ru

Суточная активность Telegram-каналов в обоих периодах одинаковая: наибольшее число новостей приходится на дневные часы (12-18 ч.), к вечеру (18-24 ч.) количество публикаций снижается. Ночью (с 24 до 7 ч.) СМИ не активны, за исключение «Радио Свобода» (8\% сообщений в первом периоде и 24\% во втором), причем количество просмотров не падает, а держится на уровне дневных публикаций. Незначительно изменилось время публикаций в канале BBC Russian: появляются сообщения в утренние и дневные часы, хотя ранее канал был активен только вечером.

Данные первого этапа исследования показали, что наиболее популярным форматом передачи контента является сочетание текста с гиперссылкой на сайт издания (см. табл. 4). Вариативно могут быть добавлены фото и эмодзи, причем эмодзи зачастую используются как самостоятельная полноценная иллюстрация содержания новостного сообщения. Практически не востребован видеоформат, аудиоформат не используется вообще, что объясняется необходимостью загрузки большего по размеру контента по сравнению с текстами и потенциально занимает у аудитории больше времени. 
Таблица 1. Аудитория каналов СМИ в Telegram

\begin{tabular}{|l|l|l|c|c|c|}
\hline \multicolumn{1}{|c|}{ Тип Сми } & \multicolumn{1}{|c|}{ Название Сми Канал } & $\begin{array}{c}\text { Число } \\
\text { подписчиков } \\
\text { (на 14.03.2017) }\end{array}$ & $\begin{array}{c}\text { Число } \\
\text { подписчиков }\end{array}$ & $\begin{array}{c}\text { Рост } \\
\text { (на 25.02.2018) }\end{array}$ & $\begin{array}{c}\text { (витории } \\
\text { (в })\end{array}$ \\
\hline Пресса & Российская газета & @rgrunews & 8301 & 28458 & 343 \\
\hline & Коммерсанть & @kmrstn & 4889 & 14651 & 297 \\
\hline Радио & Радио Свобода & @radiosvoboda & 1860 & 13390 & 720 \\
\hline & ВВС Russian & @bbcrussian & 4289 & 12157 & 283 \\
\hline Телевидение & RТ на русском & @rt_russian & 20015 & 41618 & 208 \\
\hline & Дождь & @tvrain & 9475 & 29635 & 313 \\
\hline $\begin{array}{l}\text { Интернет- } \\
\text { СМИ }\end{array}$ & Меduza & @meduzalive & 24950 & 88186 & 353 \\
\hline & Snob & @snobru & 15218 & 29302 & 193 \\
\hline
\end{tabular}

Таблица 2. Среднее число публикуемых сообщений в сутки

\begin{tabular}{|l|c|c|c|}
\hline \multicolumn{1}{|c|}{ сми } & $\begin{array}{c}\text { Первый } \\
\text { период }\end{array}$ & $\begin{array}{c}\text { Второй } \\
\text { период }\end{array}$ & общее \\
\hline $\begin{array}{l}\text { Российская } \\
\text { газета }\end{array}$ & 13 & 16,1 & 14,3 \\
\hline RT на русском & 15 & 2,7 & 9,9 \\
\hline Дождь & 8,2 & 13,9 & 10,6 \\
\hline Меduzа & 6,5 & 14,2 & 9,7 \\
\hline Коммерсанть & 7,9 & 8,8 & 8,3 \\
\hline Радио Свобода & 6,8 & 5,5 & 6,3 \\
\hline Сноб & 1,1 & 3,1 & 2 \\
\hline ВВС Russian & 1,1 & 1,4 & 8 \\
\hline Всего & 7,45 & 8,2 & \\
\hline
\end{tabular}

Таблица 3. Соотношение охвата одного поста и среднесуточная публикационная активность

\begin{tabular}{|l|c|c|c|c|}
\hline \multicolumn{1}{|c|}{ сми } & $\begin{array}{c}\text { Просмотры, \% } \\
\text { (первый период) }\end{array}$ & $\begin{array}{c}\text { Просмотры, \% } \\
\text { (второй период) }\end{array}$ & $\begin{array}{c}\text { Сообщения } \\
\text { (первыйпериод) }\end{array}$ & $\begin{array}{c}\text { Сообщения } \\
\text { (второй период) }\end{array}$ \\
\hline Сноб & 72,6 & 47,3 & 1,1 & 3,1 \\
\hline Meduza & 51 & 41 & 6,5 & 9,7 \\
\hline Коммерсанть & 48,7 & 48,4 & 7,9 & 8,8 \\
\hline Радио Свобода & 45,4 & 41 & 6,8 & 5,5 \\
\hline ВВС Russian & 37,9 & 38,1 & 1,1 & 1,25 \\
\hline $\begin{array}{l}\text { Российская } \\
\text { газета }\end{array}$ & 37,5 & 33,2 & 13 & 16,1 \\
\hline Дождь & 35 & 36,4 & 7,9 & 13,9 \\
\hline RТ на русском & 30,4 & 64,6 & 15 & 2,7 \\
\hline
\end{tabular}


Таблица 4. Формат передачи информации в первом периоде (в \% от общего числа сообщений)

\begin{tabular}{|l|c|c|c|c|c|c|c|c|}
\hline \multirow{2}{*}{ Формат } & \multicolumn{7}{|c|}{ Сми } \\
\cline { 2 - 9 } & $\mathbf{P \Gamma}$ & Коммерсанть & $\begin{array}{c}\text { Радио } \\
\text { Свобода }\end{array}$ & ВBC & $\mathbf{R T}$ & Дождь & Meduza & Snob \\
\hline Текст & 0 & 0 & 14,6 & 0 & 1 & 1,7 & 2,3 & 0 \\
\hline Текст+фото & 0 & 0 & 0,9 & 0 & 0 & 4,3 & 2,3 & 0 \\
\hline Текст+видео & 0 & 0 & 0 & 6 & 0 & 0 & 0 & 0 \\
\hline $\begin{array}{l}\text { Текст+ } \\
\text { ссылка }\end{array}$ & 96 & 90,9 & 61,5 & 53 & 3,9 & 72,3 & 71,4 & 68,8 \\
\hline Текст+эмодзи & 0 & 0 & 0 & 0 & 0 & 0,9 & 4,5 & 0 \\
\hline $\begin{array}{l}\text { Текст+фото } \\
\text { +ссылка }\end{array}$ & 4 & 2,7 & 23 & 41 & 32,3 & 2,6 & 2,3 & 25 \\
\hline $\begin{array}{l}\text { Текст+эмодзи+ } \\
\text { ссылка }\end{array}$ & 0 & 0 & 0 & 0 & 58,8 & 13 & 12 & 0 \\
\hline $\begin{array}{l}\text { Текст+эмодзи+ } \\
\text { фото +ссылка }\end{array}$ & 0 & 0 & 0 & 0 & 3,9 & 1,7 & 0 & 0 \\
\hline Фото & 0 & 0 & 0 & 0 & 0 & 2,6 & 4,5 & 6,2 \\
\hline Видео & 0 & 6,4 & 0 & 0 & 0 & 0,9 & 0 & 0 \\
\hline
\end{tabular}

Таблица 5. Формат передачи информации во втором периоде (в \% от общего числа сообщений)

\begin{tabular}{|l|c|c|c|c|c|c|c|c|}
\hline \multirow{2}{*}{ Формат } & \multicolumn{7}{|c|}{ Сми } \\
\cline { 2 - 10 } & Pг & Коммерсанть & $\begin{array}{c}\text { Радио } \\
\text { Свобода }\end{array}$ & ВBC & RT & Дождь & Meduza & Сноб \\
\hline Текст & 0 & 0 & 7,3 & 0 & 51,8 & 0 & 2,1 & 0 \\
\hline Текст+ссылка & 0 & 40,4 & 92,7 & 13,3 & 7,4 & 60,4 & 73,3 & 100 \\
\hline Текст+фото & 40,4 & 0 & 0 & 0 & 7,4 & 5,7 & 7,2 & 0 \\
\hline $\begin{array}{l}\text { Текст+фото+ } \\
\text { ссылка }\end{array}$ & 51,6 & 20,2 & 0 & 20 & 0 & 20,8 & 3,6 & 0 \\
\hline $\begin{array}{l}\text { Текст+эмодзи+ } \\
\text { ссылка }\end{array}$ & 0 & 39,4 & 0 & 66,7 & 0 & 6,5 & 10,8 & 0 \\
\hline $\begin{array}{l}\text { Текст+эмодзи+ } \\
\text { фото }\end{array}$ & 0 & 0 & 0 & 0 & 0 & 2,2 & 0 & 0 \\
\hline Фото & 0 & 0 & 0 & 0 & 29,6 & 4,3 & 0 & 0 \\
\hline Видео & 8 & 0 & 0 & 0 & 0 & 0 & 0 & 0 \\
\hline Аудио & 0 & 0 & 0 & 0 & 3,7 & 0 & 3 & 0 \\
\hline
\end{tabular}



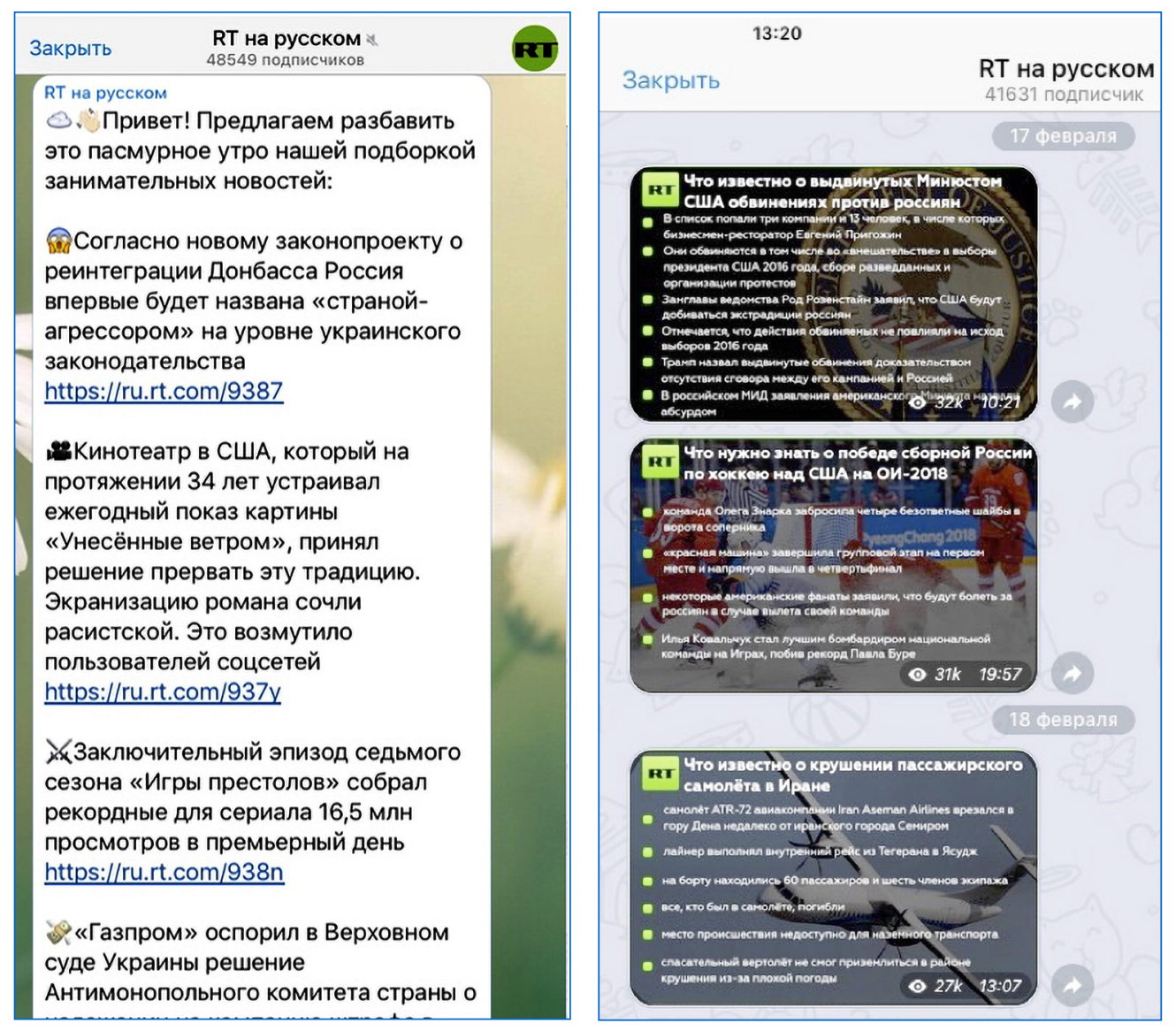

Рисунок. Подача контента в канале «RT на русском» в первом (слева) и втором (справа) периодах исследования

Спустя год стратегия дистрибуции новостей претерпела некоторые изменения: СМИ отходят от единообразия форм передачи контента (текст+ссылка), увеличилась частота использования формата текст+ссылка+фото, но сократилась иллюстрация новостей эмодзи, причем эмодзи теперь используются не для иллюстрации новостей, а для маркировки срочных сообщений (см. табл. 5). Видео и аудио по-прежнему не востребованы. Аудио использует только Meduza для продвижения собственных аудиоподкастов «Медуза в курсе». Короткие видеоролики (от 40 сек. до минуты) публикует только «Российская газета» для иллюстрации постов, следующих за видео, причем просмотры видео ниже, чем просмотры новости, которую иллюстрирует видео.

«Российская газета», у которой в первом периоде подавляющее большинство публикаций составляло сочетание текста и ссылки (96\%), во втором периоде полностью отказалась от стратегии унификации контента и сделала акцент на разнообразный иллюстративный материал. Можно также отметить нововведение канала газеты в Telegram: анонсы трансляций спортивных событий (например, матчей «Спартак» - «Атлетико», «Зенит» - «Селтика» 
и игр сборной России по хоккею на Олимпиаде в Южной Корее). Это также направлено на привлечение аудитории мессенджера к сайту газеты, поскольку внутри канала трансляции матчей не ведутся, хотя функционал мессенджера позволяет вести прямую текстовую трансляцию.

За прошедший год самой большой трансформации подверглась стратегия канала «RT на русском». В первом периоде основным типом передачи контента было сочетание текста, эмодзи и ссылка (58,8\%), а во втором - канал полностью отказался от эмодзи, превалируют текстовые сообщения (51,8\%) и инфографика (29,6\%). Интересно, что ссылки на сайт телеканала во втором периоде не публикуются (см. рис.).

Практически полностью отказался от использования эмодзи и телеканал «Дождь»: в первом периоде 15,6\% сообщений содержали эмодзи, иллюстрирующие произошедшее или передающие отношение редакции к событию, во втором с их помощью маркируются только срочные новости. Телеканал оставил утренние обзоры новостей и добавил в Telegram вечерние колонки от ведущих «Дождя».

Изменения произошли и в Telegramканале BBC Russian: CMИ перешло на длинные анонсы новостей дня, сопровождаемые ссылкой на сайт и эмодзи, хотя в первом периоде эмодзи не использовались. В подборках новости разделяются на главные и менее важные. По-прежнему отсутствует публикационная активность в выходные дни.

\section{Заключение}

Стремительно развивающиеся технологии трансформировали окружающую действительность, привычки индивидов, общество стратифицируется по новым принципам, связанным с медиапотреблением и медиаграмотностью (Вартанова, 2017). Пользователи Интернета, в равной степени цифровые аборигены и цифровые мигранты, не в состоянии воспринять и обработать весь поток информации, производимой в онлайн-среде. Перепроизводство информации заставляет СМИ искать новые средства, чтобы завоевать внимание аудитории. Популярность мессенджеров у россиян заставила СМИ обратить внимание на данные сервисы и предлагать свой контент аудитории на удобной ей площадке. Аудитория использует мессенджер не только для межличностного общения, но и для чтения информационных каналов 8 .

Изучение дистрибуции новостей в Telegram-каналах показало, что СМИ еще только формируют стратегии собственного присутствия в мессенджере. Часть СМИ отказалась от унификации сообщений в пользу разнообразия форматов подачи новостей, но превалирующим типом передачи контента все равно остается сочетание текста и гиперссылки, ведущей на сайт СМИ. Стратегия привлечения аудитории используется всеми проанализированными СМИ (исключение - канал «RT на русском», у которого всего 7,4\% постов содержат гиперссылки). СМИ не используют в полной мере функционал площадки (например, «Российская газета» не проводит текстовую трансляцию футбольного матча в Telegram, а ведет аудиторию на свой сайт, где и организована трансляция). Пока конверсия просмотров в переходы на сайт достаточно мала и, по оценкам экспертов, варьируется от 3\%9 до 7\%10.

За счет того, что коммуникация в мессенджере носит преимущественно односторонний характер, усложняется формирование сообщества медиа. Так, в изученные периоды лишь Meduza и «Дождь» налаживали обратную связь с пользователями за счет голосований с помощью эмодзи. Только Meduza завела отдельный канал @meduzalovesyou, куда читатели могут отправлять сообщения, делиться мнениями об опубликованных постах или предлагать новости. 
Сохраняется тенденция, согласно которой частота постинга влияет на охват новости: чем больше сообщений в день публикуется в канале СМИ, тем ниже охват поста.

Привлечение аудитории к сайту остается основной стратегией, как мы полагаем, по причине того, что монетизировать контент, размещаемый на сайте, легче, чем контент в мессенджере. В Telegram возможно публиковать нативные и рекламные посты, а на сайте помимо этого размещаются спецпроекты, баннеры, контекстная и таргетированная реклама. Кроме того, выявить социально-демографические характеристики аудитории сайта значительно проще, чем аудитории канала в Telegram и, соответственно, проще продавать рекламодателям аудиторию сайта. На сегодняшний день существуют проблемы с измерением аудитории канала, поскольку Telegram не предложил официальных инструментов для аудиторных измерений. Для анализа можно использовать сторонние сервисы (Telemetr, Combot и др.).

Данные проведенного исследования показывают, что популярность СМИ в Telegram растет, значительно увеличилось число подписчиков. Все СМИ, представленные на обоих этапах исследования, продолжают распространять новости через Telegramканалы. Единственное исключение - «Российская газета». Канал @rgrunews перестал функционировать 16 апреля 2018 г., в день блокировки мессенджера Роскомнадзором, хотя его аудитория значительно выросла.

Сложно сделать точный прогноз, как будут развиваться Telegram-каналы СМИ и как будут трансформироваться стратегии дистрибуции новостей. Мы предполагаем, что СМИ продолжат рассматривать Telegram как дополнительную площадку для увеличения трафика на основном ресурсе. Данное умозаключение подкреплено не только полученными автором эмпирическими данными, но и результатами исследования Newman Lab. Опрос создателей Telegramканалов российских общественно-политических СМИ показал, что они руководствовались следующими мотивами: «Мы пытаемся быть представлены на разных платформах», «Возможность отправлять уведомления аудитории - важная причина присутствия СМИ в Telegram», "Для нас канал в Telegram - это поле для экспериментов»11.

Безусловно, исследование дистрибуции контента в Telegram необходимо продолжать, поскольку мессенджер развивается и продолжает набирать популярность, увеличивать аудиторию. Расширение выборки на следующем этапе позволит получить более точные данные и посмотреть, как изменились стратегии общественнополитических СМИ в Telegram.

\section{Примечания}

${ }^{1}$ Mediascope расширила измерения мобильного Интернета до всей России / Mediascope. Режим доступа: https://mediascope.net/news/1067271/ (дата обращения: 06.12.2019).

2 Проект Web Index/Mediascope. Режим доступа: https://webindex.mediascope.net/ top-resources/projects (дата обращения: 06.12..2019).

3 Аудитория Рунета на мобильных устройствах обогнала десктопную / Mediascope. Режим доступа: https://mediascope.net/news/819428/?sphrase_id=195366 (дата обращения: 06.12.2019). 
4 Самые популярные мессенджеры в России - WhatsApp, Viber, Skype / Deloitte. Peжим доступа: https://www2.deloitte.com/ru/ru/pages/about-deloitte/deloitte-inpress/2018/samye-populyarnye-rossii-messendzhery-whatsapp-viber-skype.html (дата обращения: 09.06.2019).

5 Топ-платформы и 100 виртуальных русскоязычных медиаресурсов / Brand Analytics. Режим доступа: https://br-analytics.ru/blog/top-100-january-2020/ (дата обращения: 18.02.2020).

${ }^{6}$ Аудитория Telegram-каналов 2019 / TGStat. Режим доступа: https://tgstat.ru/ research (дата обращения: 18.02.2020).

7 Там же.

8 По данным ФОМ, 18\% пользователей Telegram указывают данную причину как основную.

9 Паранько С., Сидорова О. Модели медиапотребления. Что люди читают, почему, когда и как. М.: UX-лаборатория Mail.Ru Group, 2017.

10 Ломаченко А. Зачем маркетологу Telegram и как правильно в нем продвигаться // Энциклопедия маркетинга. Режим доступа: https://www.marketing.spb.ru/ lib-comm/internet/Telegram.htm (дата обращения: 11.06.2019).

${ }^{11}$ Valeeva A. Chat App Telegram, not Much Loved by the Russian Government, Still Attracts a Loyal Readership for News. Newman Lab. Режим доступа: https://www. niemanlab.org/2017/07/chat-app-telegram-not-much-loved-by-the-russian-government-still-attracts-a-loyal-readership-for-news/ (дата обращения: 11.06.2019).

\section{Библиография}

Андрашитов Д.С., Иосебашвили Л.З., Цедилкин И.Д. Информационная безопасность мобильных приложений // Наука и общество в эпоху технологий и коммуникаций: мат. междунар. науч.-практ. конф. 3 декабря 2015 г. М.: Моск. ун-т им. С.Ю. Вите, 2016. С. 840-845.

Вартанова Е.Л. Прорывные медиатехнологии в контексте общественного запроса // МедиаАальманах. 2017. № 4. С. 8-13.

Голошубина О.К. Разговор в мессенджере как специфический жанр интернет-коммуникации // Вестн. Омск. ун-та. 2015. № 1 (75). С. 208-212.

Градюшко А.А. Мессенджеры в структуре творческой деятельности журналистов // Мультимедийная журналистика: сб. науч. тр. междунар. науч.-практ. конф. / под ред. В.П. Воробьева. Мн: Белорус. гос. ун-т, 2018. С. 8-14.

Епишкин И.И. Telegram-каналы: причины запуска и инструменты продвижения // МедиаАльманах. 2017. № 3. С. 30-41.

Коноплев Д.Э. Telegram как новая среда коммуникации в СМИ и соцсетях // Знак: проблемное поле медиаобразования. 2017. № 3 (25). С. 198-200.

Линд А.В., Махов А.А. Мессенджер Telegram как эффективный инструмент в работе с целевыми аудиториями // Актуальные проблемы коммуникации: теория и практика: мат. VIII Всерос. науч.-практ. конф. Уфа: Башкирск. гос. ун-т, 2016. С. 119-126.

Манукова Е.Ю., Захарова М.В. Использование сервисов мгновенного обмена сообщениями в современной массовой коммуникации // Современная филология: мат. V междунар. науч. конф. Самара: Изд-во АСГАРД, 2017. С. 85-87. 
Сенаторов A. Telegram: Как запустить канал, привлечь подписчиков и заработать на контенте. М.: Альпина Паблишер, 2018.

Сейдаметова 3.С., Асанова У.Б., Костина Е.Г. Системы мгновенного обмена сообщения: проектирование и разработка приложения Atalk // Информационно-компьютерные технологии в экономике, образовании и социальной сфере. 2016. № 2 (12). С. 5-21.

Соколова Д.В. Дистрибуция новостного контента в мессенджере Telegram // Медиаскоп. 2017. Вып. 4. Режим доступа: http://www.mediascope.ru/2380

Степанов В.А. Мессенджер Telegram в информационном пространстве Беларуси / Мультимедийная журналистика: сб. науч. тр. междунар. науч.-практич. конф. / под ред. В.П. Воробьева. Мн: Белорус. гос. ун-т, 2018. С. 240-245.

Чабаненко М.В. Сравнение подходов в использовании возможностей мессенджеpa Telegram для распространения сообщений СМИ // Мультимедийная журналистика: сб. науч. тр. междунар. науч.-практ. конф. / под ред. В.П. Воробьева. Мн: Белорус. гос. ун-т, 2018. С. 256-261.

Dodds T. (2019) Reporting with WhatsApp: Mobile Chat Applications' Impact on Journalistic Practices. Digital Journalism 7 (6): 725-745. DOI: 10.1080/21670811.2019.1592693

Domingo D., Masip P., Costera Meijer I. (2015) Tracing Digital News Networks: Towards an Integrated Framework of the Dynamics of News Production, Circulation and Use. Digital Journalism 3 (1): 53-67.

Jakobsen J.B. (2015) A Practical Cryptanalysis of the Telegram Messaging Protocol. Aarhus: Aarhus University.

Kemp S. (2018) Global Digital Report. Were Social, January 30. Режим доступа: https:// wearesocial.com/blog/2018/01/global-digital-report-2018

Mahin S.A. (2016) Evaluation of the Effect of Virtual Works. Structure on User's Social Relations (by Comparasion of Facebook and Telegram). In: Mediasnumeriques\&Communic ationelectronique, Actes de colloque. Universite de Havre. pp. 817-826.

Negreira-Rey M.-C., Lopez-Garcia X., Lozano-Aguiar L. (2017) Instant Messagung Networks as a New Channel to Spread the News: Use of WhatsApp and Telegram in the Spanish Online Media of Proximity. Advances in Intelligent Systems and Computing, vol. 571, pp. 64-72. 